\title{
Tooth Marker of Ecological Abnormality: the Interpretation of Stress in Extinct Mega Herbivores (Proboscideans) of the Siwaliks of Pakistan
}

\author{
Muhammad Ameen ${ }^{1}$, Abdul Khan ${ }^{1}$, Rana Ahmad ${ }^{1}$, Muhammad Ijaz², and Muhammad \\ $\operatorname{Imran}^{1}$ \\ ${ }^{1}$ University of the Punjab \\ ${ }^{2}$ University of Agriculture Faisalabad
}

September 25, 2021

\begin{abstract}
Climate effects habitat and define species physiology. Climatic regimes were different in past and adaptability of different species varied. Climate change causes certain stress on animal, recorded as Enamel Hypoplasia (EH). Proboscideans, the mega herbivores were extensively represented in the Siwaliks of Pakistan between Middle Miocene to Pleistocene ( $\sim 15.2-\sim 1.0 \mathrm{Ma})$. The study is carried out on 15 species from 9 genera and 4 families using 319 teeth from 266 individual quarries. Our results revealed 20.06\% (64/319) teeth infected by EH. Family Deinotheriidae faced higher stress during the terminal of middle Miocene (EH 25\%). Dental structure indicate that this family preferred soft vegetation like C3 plants and failed to survive in grassland ecology at the onset of Late Miocene ( ${ }^{10-9} \mathrm{Ma}$ ). Gomphotheriids (EH 21.05\%) and Stegodontids (EH 23.40\%) survived through warm and dry climatic conditions of the Late Miocene, but could not survive the cool and dry climate of Plio-Pleistocene where grasslands were abundant with less browsing activity. Family Elephantidae (EH 8.75\%) was successful in drier conditions, and utilized the exclusive $\mathrm{C} 4$ diet in open grasslands as efficient grazers, indicated by their tooth morphology. Elephantids were dominant of the proboscideans in open grassland and drier climate during Plio-Pleistocene in Indian subcontinent. We assume that change in the Siwalik climate was governed by microclimate as in the present day Siwaliks grasslands are widely distributed at low altitudes with lower mean annual precipitation and forestlands still persist in Myanmar and Nepal which receives more rainfall and have lower mean annual temperature.
\end{abstract}

Tooth Marker of Ecological Abnormality: the Interpretation of Stress in Extinct Mega Herbivores (Proboscideans) of the Siwaliks of Pakistan

MUHAMMAD AMEEN

Department of Zoology, University of the Punjab, Lahore, 54000, Pakistan.

Mameen019@gmail.com

ABDUL MAJID KHAN*

Department of Zoology, University of the Punjab, Lahore, 54000, Pakistan.

majid.zool@pu.edu.pk

RANA MANZOOR AHMAD

Department of Zoology, University of the Punjab, Lahore, 54000, Pakistan.

biologist321@gmail.com 


\section{MUHAMMAD IMRAN}

Department of Zoology, University of the Punjab, Lahore, 54000, Pakistan.

pinkrose034550@gmai.com

Department of Zoology, University of the Punjab, Lahore, 54000, Pakistan.

MUHAMMAD UMAR IJAZ

Department of Zoology, University of Agriculture, Faisalabad, 38040, Pakistan.

umar.ijaz@uaf.edu.pk

Corresponding Author: majid.zool@pu.edu.pk

\section{Hosted file}

EH in Siwalik Proboscideans.docx available at https://authorea.com/users/436680/articles/ 538834-tooth-marker-of-ecological-abnormality-the-interpretation-of-stress-in-extinctmega-herbivores-proboscideans-of-the-siwaliks-of-pakistan 